\title{
Verzeichnis der Gruppen
}

\begin{tabular}{|c|c|c|c|}
\hline I & Nr. & $1-3$ & Dame und Lăufer gegen Dame \\
\hline II & 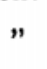 & $4-8$ & $\begin{array}{l}\text { Dame und Lăufer gegen Dame und andere } \\
\text { Streitkräfte. }\end{array}$ \\
\hline III $^{1}$ & , & $9-13$ & Dame und Springer gegen Dame. \\
\hline IV & $"$ & $14-25$ & $\begin{array}{l}\text { Dame und Springer gegen Dame und andere } \\
\text { Streitkräfte. }\end{array}$ \\
\hline V & $"$ & $26-34$ & $\begin{array}{l}\text { Dame, Springer und Bauer gegen Dame und } \\
\text { andere Streitkrafte. }\end{array}$ \\
\hline $\mathrm{VI}^{2}$ & $"$ & $35-49$ & $\begin{array}{l}\text { Dame und andere Streitkrafte gegen Dame und } \\
\text { andere Streitkrafte. }\end{array}$ \\
\hline VII & $n$ & $50-53$ & Dame und Bauern gegen Dame und Bauern. \\
\hline VIII & $"$ & $54-59$ & $\begin{array}{l}\text { Läufer, Springer und Bauern gegen Bauern, von } \\
\text { welchen einer das Umwandlungsfeld erreicht. }\end{array}$ \\
\hline IX & $"$ & $60-63$ & $\begin{array}{l}\text { Lăufer, Springer und Bauern gegen Dame und } \\
\text { andere Streitkräfte. }\end{array}$ \\
\hline $\mathbf{X}$ & $"$ & $64-65$ & $\begin{array}{l}\text { Zwei Springer und Bauern gegen Dame und } \\
\text { andere Streitkrafte. }\end{array}$ \\
\hline $\mathrm{XI}$ & " & $66-70$ & Turm, Läufer und Bauern gegen Dame und Bauern. \\
\hline XII & $"$ & $71-79$ & $\begin{array}{l}\text { Turm, Springer und Bauern gegen Dame und } \\
\text { andere Streitkrafte. }\end{array}$ \\
\hline XIII & $"$ & $80-82$ & $\begin{array}{l}\text { Drei kleine Figuren und Bauern gegen Dame } \\
\text { und andere Streitkräfte. }\end{array}$ \\
\hline XIV & " & $83-85$ & $\begin{array}{l}\text { Eine kleine Figur und Bauern gegen Turm, mit } \\
\text { oder ohne Bauern. }\end{array}$ \\
\hline XV & $"$ & $86-89$ & $\begin{array}{l}\text { Zwei kleine Figuren und Bauern gegen Turm } \\
\text { und Bauern. }\end{array}$ \\
\hline XVI & " & $90-108$ & $\begin{array}{l}\text { Taktische Manöver, um einen Bauer zur Dame } \\
\text { zu fuhren. }\end{array}$ \\
\hline XVII & , & $109-115$ & Verschiedenartige Gewinnstudien. \\
\hline XVIII & $"$ & $116-121$ & Verschiedenartige Remisstudien. \\
\hline$\underset{\mathrm{XX}^{3}}{\mathrm{XIX}}$ & $"$ & $\left.\begin{array}{l}122-135 \\
136-150\end{array}\right\}$ & Patstudien. \\
\hline
\end{tabular}

${ }^{1}$ In den Gruppen III, IV, VII, XI figurieren in erster Linie die. jenigen Studien, bei welchen sich Bauern in Damen umwandeln.

${ }^{2}$ Die Kompositionen dieser Gruppe sind charakterisiert durch Opfer, welche den Gewinn der Dame vorbereiten, und zwar entweder dadurch, $\mathrm{daB}$ die Dame gezwungen wird, ihren Platz zu wechseln (Nr. 35- 40), oder $\mathrm{daB}$ ein sie schutzender Stein abgelenkt wird (Nr. 44, 46, 48), oder daB eine sie preisgebende Linie geöffnet wird (Nr. 41, 44, 47, 49), oder endlich, daß dem schwarzen König ein Fluchtfeld genommen wird, was ebenfalls den Damenverlust verursacht (Nr. 41, 42, 43, 44, 45).

${ }^{3}$ Die Studien dieser Gruppe weisen reine und ökonomische Schlubstellungen ohne untätige Bauern auf. 
Quatre études présentées comme "Première publication", ont été publiées alors que le présent ouvrage était déjà en cours d'impression:

$$
\begin{aligned}
& \text { No } 5 \text { dans la "Bohemia“ - Juin } 1908 \\
& \text { No 35. dans la "Deutsche Schachzeitung“ - Juillet } 1908 \\
& \begin{array}{l}
\text { No } 44 \\
\text { No }
\end{array} 49 \text { dans la "Stratégie“ - Aout } 1908
\end{aligned}
$$

Wahrend der Drucklegung des Buches sind vier Studien anderweit veröffentlicht worden, welche als „Erste Veröffentlichung" bezeichnet sind:

Nr. 5 in der "Bohemia“ - Juni 1908

Nr. 35 in der "Deutschen Schachzeitung" - Juli 1908

Nr. 44

Nr. 49$\}$ in der „Stratégie“ - August 1908 